\title{
ANALISIS SISTEM PENERIMAAN PAJAK KENDARAAN BERMOTOR DI UPTD SAMSAT MANADO
}

\author{
Wanda Regina Umboh ${ }^{1}$, Jantje J. Tinangon ${ }^{2}$, Dhullo Afandi ${ }^{3}$ \\ ${ }^{1,2,3}$ Jurusan Akuntansi, Fakultas Ekonomi dan Bisnis, Universitas Sam Ratulangi, Jl. Kampus UNSRAT \\ Manado, 95115, Indonesia \\ E-mail: wandaumboh1610@gmail.com
}

\begin{abstract}
One source of regional income is drived from motor vehicle tax (PKB). Motor vehicle tax that is handed over to the regions which is regulated through Government Regulation concerning regional taxes and the One Roof Single Administrative System (SAMSAT) as an administrative system that is designed to facilitate and accelerate the service of the public interest. The purpose of this study is to analyze the adequacy of the system of moto vehicle tax receipts UPTD SAMSAT Manado. The type of research used is qualitative research only present the data as it is but also attempts to interpret correction as an exixsting factor that includes the viewpoint or process that continues. The result of the study show that internal control system, has been running well and effectively. In the future the UPTD SAMSAT Manado can make other alternatives in PKB payment.

Keywords: procedure; system; motor vehicle tax; internal control
\end{abstract}

\section{PENDAHULUAN}

Pajak secara umum dapat diartikan sebagai iuran atau pemungutan yang dilakukan oleh pemerintahan dari masyarakat berdasarkan Undang-Undang dan hasilnya digunakan demi pembiayaan pengeluaran umum negara. Menurut Undang-Undang Republik Indonesia Nomor 17 tahun 2003 tentang keuangan negara, pendapatan negara berasal dari penerimaan perpajakan, penerimaan negara bukan pajak Penerimaan Negara Bukan Pajak (PNBP), serta penerimaan hibah dari dalam negeri dan luar negeri. Meskipun pendapatan di sektor pajak lebih besar dibandingkan dengan pendapatan dari sektor lain, tetapi dalam penerimaan Pajak Kendaraan Bermotor (PKB) atau Pendapatan Asli Daerah (PAD) skala persentase masih kurang dari perencanaan yang ditetapkan Wardani dan Juliansya (2018).

Penggolongan pajak berdasarkan lembaga pemungutannya di Indonesia dapat dibedakan menjadi 2 (dua) yaitu pajak pusat dan pajak daerah. Pajak pusat adalah pajak-pajak yang dikelola oleh pemerintah pusat, pajak-pajak yang dikelola oleh pemerintah pusat meliputi Pajak Penghasilan ( $\mathrm{PPh}$ ), Pajak Pertambahan Nilai (PPN), Pajak Penjualan atas Barang Mewah (PPnBM), bea materai, dan Pajak Bumi dan Bangunan (PBB) sektor P-3. Pajak daerah adalah pajak-pajak yang dikelola oleh pemerintah daerah. Teori development from below berpendapat bahwa orang akan lebih bersedia membayar pajak kepada pemerintah daerah dibandingkan kepada pemerintah pusat karena dapat secara mudah melihat manfaat langsung pembangunan daerah (Anggoro 2017:45). Pajak yang di pungut oleh Pemerintah Daerah meliputi pajak Provinsi dan pajak Kabupaten/Kota. Pajak daerah juga merupakan salah satu penerimaan yang penting di pemerintahan Provinsi, salah satunya adalah pajak kendaraan bermotor.

Sistem Administrasi Manunggal Satu Atap (SAMSAT) sebagai suatu sistem administrasi yang dibentuk untuk memperlancar dan mempercepat pelayanan kepentingan masyarakat. Samsat merupakan sistem kerjasama secara terpadu antara Polri, Dinas Pendapatan, dan PT. Jasa Raharja (PERSERO) dalam pelayanan penerbitan STNK dan Tanda Nomor Kendaraan Bermotor yang dikaitkan dengan pemasukan uang ke kas negara baik 
melalui Pajak Kendaraan Bermotor (PKB), Bea Balik Nama Kendaraan Bermotor (BBNKB), dan Sumbangan Wajib Dana Kecelakaan Lalu Lintas Jalan (SWDKLJJ).

Secara kelembagaan Unit Pelaksanaan Teknis Dinas (UPTD) pelayanan pendapatan daerah berada di bawah Dinas Pendapatan Daerah Provinsi. UPTD Pelayanan Pendapatan Daerah mempunyai tugas pokok melaksanakan pemungutan pendapatan daerah sesuai dengan bidang teknisnya, dalam pelaksanaan operasional mempunyai fungsi: (a) melakukan pendaftaran dan penetapan penagihan dan pelaporan pendapatan daerah; (b) melakukan penatausahaan pemungutan pendapatan daerah; dan (c) memberikan pelayanan kepada masyarakat. Undang-undang Nomor 34 Tahun 2000 tentang perubahan atas Undang-Undang Nomor 18 Tahun 1997 tentang Pajak Daerah dan Retribusi Daerah, dan Peraturan Pemerintah Nomor 65 Tahun 2001 tentang pajak yang mengatur pajak daerah sesuai dengan pembagian administrasi daerah. Pajak daerah dikelompokkan menjadi dua yaitu Pajak Daerah Tingkat I (Provinsi) dan Pajak Daerah Tingkat II (kabupaten dan kota). Pajak yang menjadi hak Pemerintahan Daerah Tingkat I salah satunya adalah Pajak Kendaraan Bermotor (PKB), dimana jenis Pajak Daerah Tingkat I terdiri dari: Pajak Kendaraan Bermotor (PKB), Bea Balik Nama Kendaraan Bermotor (BBNKB), dan Kendaraan diatas Air, Pajak Bahan Bakar Kendaraan Bermotor (PBBKB), dan Pajak Pengambilan dan Pemanfaatan Air Bawah Tanah dan Air Permukaan.

Pajak Kendaraan Bermotor dipungut di wilayah tempat kendaraan bermotor terdaftar. Pajak Kendaraan Bermotor yang diterima oleh Pemerintah tidaklah sedikit, mengingat semakin bertambahnya Wajib Pajak untuk Pajak Kendaraan Bermotor dan penerapan tarif pajak progresif yang mulai diterapkan oleh Pemerintah Daerah pada tahun 2012. Hal ini membuat Pajak Kendaraan Bermotor memiliki potensi yang dapat dikembangkan. Sistem pemungutan PKB dilaksanakan dengan Sistem Administrasi Manunggal di Bawah Satu Atap yang dikenal dengan Samsat (Kansil, et al., 2018). Peraturan Daerah Provinsi Sulawesi Utara Nomor 7 Tahun 2011 pajak kendaraan bermotor yang terutang dipungut di wilayah daerah tempat kendaraan bermotor didaftarkan, pemungutan pajak kendaraan bermotor dilakukan bersamaan dengan penerbitan Surat Tanda Nomor Kendaraan Bermotor dan pemungutan pajak tahun berikutnya dilakukan di kas daerah atau bank yang ditunjuk oleh Gubernur.

\section{TINJAUAN PUSTAKA}

Akuntansi. Tujuan akuntansi secara keseluruhan adalah memberikan informasi yang dapat digunakan dalam pengambilan keputusan. Menurut APB Statement No.4 (tahun 1970) yang berjudul "Basic Concepts and Accounting Principles Underlying Financial Statements of Business Enterprises". Akuntansi merupakan proses identifikasi, pencatatan dan komunikasi terhadap transaksi ekonomi dari suatu entitas. Secara umum terdapat tiga aktivitas dalam akuntansi yaitu akuntansi identifikasi, akuntansi pencatatan, dan akuntansi komunikasi (Wibowo dan Arif 2008:1).

Pajak. Pajak merupakan sarana pemerintah yang digunakan untuk memperoleh dana atau iuran dari masyarakat dan digunakan untuk membiayai pengelolaan negara, seperti pembangunan baik dari segi fisik maupun non fisik. Pembangunan ini terus berlangsung dan berkesinambungan untuk tujuan meningkatkan kesejahteraan rakyat. Para ahli di bidang perpajakan mendefinisikan pengertian pajak dengan berbagai pendapat yang berbeda. Pajak adalah iuran masyarakat kepada negara yang terutang oleh yang wajib membayarnya menurut peraturan-peraturan umum dengan tidak mendapat prestasi kembali yang langsung dapat ditunjuk dan yang gunanya adalah untuk membiayai pengeluaran umum berhubungan tugas negara untuk menyelenggarakan pemerintahan (Sari, 2013:34). Kesadaran masyarakat wajib pajak merupakan perilaku wajib pajak berupa pandangan atau persepsi yang melibatkan keyakinan, pengetahuan dan penalaran serta kecenderungan untuk bertindak sesuai dengan stimulus yang diberikan oleh sistem dan ketentuan perpajakan yang berlaku. Masalah yang 
sering muncul adalah rendahnya kepatuhan masyarakat dalam membayar pajak kendaraan bermotor. Pada tahun 2009, DPRD telah menyetujui dan mengesahkan rancangan UndangUndang Pajak Daerah dan Retribusi Daerah (RUU PDRD) menjadi Undang-Undang, sebagai pengganti dari Undang-Undang Pajak Daerah dan Retribusi Daerah (UU PDRD). Perubahan Undang-Undang memiliki tiga tujuan yaitu yang pertama memberikan kewenangan yang lebih besar kepada daerah dalam perpajakan dan retribusi sejalan dengan semakin besarnya tanggung jawab daerah dalam penyelenggaraan pemerintahaan dan pelayanan kepada masyarakat. Tujuan yang kedua meningkatkan akuntabilitas daerah dalam penyediaan layanan dan penyelenggaraan pemerintahan dan sekaligus memperkuat otonomi daerah, dan tujuan yang ketiga memberikan kepastian bagi dunia usaha mengenai jenis-jenis pungutan daerah dan sekaligus memperkuat dasar hukum pemungutan pajak daerah dan retribusi daerah. Menurut Sayuti dan Faisal (2014), pajak kendaraan bermotor dan bea balik nama kendaraan bermotor menjadi prioritas usaha intensifikasi pajak karena memiliki potensi yang besar dalam mendorong peningkatan pendapatan daerah.

Pajak Daerah. Undang-Undang Nomor 28 Tahun 2009 tentang pajak daerah dan retribusi daerah adalah Pajak Kendaraan Bermotor, Bea Balik Nama Kendaraan Bermotor, Pajak Bahan Bakar Kendaraan Bermotor, Pajak Air Permukaan, Pajak Rokok. Subjek pajak kendaraan bermotor adalah orang pribadi atau badan yang memiliki dan/atau menguasai kendaraan bermotor.Wajib pajak badan, kewajiban perpajakannya diwakili oleh pengurus atau kuasa badan tersebut. Undang-Undang Nomor 32 Tahun 2004 atas Pajak daerah dan retribusi daerah ditetapkan dengan Undang-Undang yang pelaksanaannya di daerah diatur lebih lanjut dengan Perda.

Penelitian terdahulu. Agustin dan Putra (2019) membuktikan bahwa kesadaran masyarakat tidak berpengaruh signifikan terhadap kepatuhan wajib pajak dalam membayar pajak kendaraan bermotor. Panjaitan dan Simarmata (2018) menunjukkan bahwa pajak kendaraan bermotor berpengaruh positif terhadap pendapatan pajak daerah Kabupaten Simalungun dan Kota Pematangsiantar. Madundang dan Ilat (2014) menunjukkan bahwa tata cara dan prosedur perhitungan pajak kendaran bermotor dan bea balik nama kendaraan bermotor di UPTD Kota Bitung sudah sesuai dengan garis kebijakan Pemerintah Daerah Provinsi Sulawesi Utara.

\section{METODE PENELITIAN}

Jenis penelitian yang digunakan adalah deskriptif kualitatif yang mempelajari masalah-masalah yang ada serta tata kerja yang berlaku. George, et al. (2017) menyatakan bahwa data kualitatif adalah data yang tidak dapat diukur dengan skala numerik atau angka dan disajikan secara deskriptif berupa penjelasan atau gambaran mengenai sesuatu. Penelitian kualitatif tidak hanya menyajikan data apa adanya melainkan juga berusaha menginterpretasikan korelasi sebagai faktor yang ada yang berlaku meliputi sudut pandang atau proses yang sedang berlanjut. Jenis data yang digunakan penelitian ini merupakan data deskriptif kulitatif berupa kata-kata tertulis atau lisan dari orang-orang dan pelaku yang dapat diamati, data yang digunakan berupa formulir pendaftaran, persyaratan dokumen asli berupa fotokopi KTP, SKPD, Flowchart mekanisme pembayaran PKB.

Data primer adalah data yang dikumpulkan langsung dan belum pernah dikumpulkan di periode waktu sebelumnya. Data ini merupakan data utama yang digunakan untuk penelitian, biasanya berbentuk observasi langsung dengan pihak tertentu. Tujuan analisis adalah menyederhanakan data dalam bentuk yang lebih mudah dibaca dan diinterpretasi. Penelitian strukturalistik, data yang berupa kualitatif (kata-kata) dikuantifikasi terlebih dahulu kemudian dianalisis secara statistik bertujuan untuk menjelaskan fenomena, menguji hipotesis kerja dan mengangkat sebagai temuan berupa verifikasi terhadap teori lama dan teori baru. 


\section{HASIL PENELITIAN DAN PEMBAHASAN}

\subsection{Hasil penelitian}

UPTD Samsat Manado secara kelembagaan berada dibawah Dinas Pendapatan Daerah Provinsi Sulawesi Utara. Samsat merupakan suatu sistem kerjasama secara terpadu antara Polri, Dinas Pendapatan Provinsi, dan PT. Jasa Raharja (PERSERO) dalam pelayanan untuk menerbitkan STNK dan Tanda Nomor Kendaraan Bermotor yang dikaitkan dengan pemasukan uang ke kas negara baik melalui Pajak Kendaraan Bermotor (PKB), Bea Balik Nama Kendaraan Bermotor, dan Sumbangan Wajib Dana Kecelakaan Lalu Lintas Jalan (SWDKLJJ), dan dilaksanakan pada satu kantor yang dinamakan "Kantor Bersama Samsat". UPTD Samsat Manado beralamat di Jl. 17 Agustus Nomor 123 Manado, berbatasan dengan halaman Kantor Bank Indonesia Cabang Manado yang berhadapan dengan Kantor Gubernur Provinsi Sulawesi Utara, lokasi kantor ini berada di Kelurahan Tanjung Batu, Kecamatan Wanea Kota Manado.

Pajak Kendaraan Bermotor yang mana penghitungan berdasarkan pengenaannya, nilai jual dan besar tarif pajak yang akan dikenakan, bagi orang yang memiliki Kendaraan Bermotor. Penghitungan adalah suatu rangkaian kegiatan penghimpunan atau untuk menentukan besarnya jumlah pajak yang terutang. Langkah-langkah yang dilakukan dalam penghitungan Pajak Kendaraan Bermotor terlebih dahulu harus mengetahui jenis/merek/tipe, tahun pembuatan, nilai jual kendaraan bermotor, bobot, dasar pengenaan, dan tarif yang ditetapkan. Prosedur pelaporan PKB dengan menggunakan sistem internal adalah sebagai berikut:

1. Wajib pajak menyerahkan slip bukti pembayaran kepada petugas pencetak SKPD atau pemberitahuan pajak.

2. Petugas mencetak SKPD atau pemberitahuan selanjutnya diajukan kepada kepala seksi penetapan untuk diberikan paraf pengesahan dan dikembalikan kepada petugas pencetak kemudian diserahkan kepada bendahara penerima pembantu.

3. Bendahara penerima bertanggung jawab mendistribusikan SKPD asli atau pemberitahuan pajak pada petugas penyerahan. SKPD kedua untuk bendahara penerima untuk di buat laporan SKPD ketiga diteruskan kepada petugas PT. Jasa Raharja untuk arsip. SKPD keempat diberikan kepada Kepala Seksi Pajak, Retribusi dan PPL untuk arsip. SKPD kelima untuk diserahkan pada kepala Bidang Pajak di Dispenda Sulut untuk arsip.

4. Petugas penyerahan menyerahkan SKPD asli kepada wajib pajak dengan melakukan pencatat pada buku penyerahan yang ditandatangani oleh wajib pajak.

5. Jika SKPD atau pemberitahuan pajak hilang akan dibuat duplikat, wajib pajak harus mengikuti mekanisme pengurusan PKB/BBNKB dengan melampirkan surat keterangan hilang dari kepolisian SPPKB lama dan fotokopi arsip SKPD atau pemberitahuan pajak terakhir yang disahkan dengan paraf kepala seksi penetapan dan penerimaan $\mathrm{PKB} / \mathrm{BBNKB}$.

6. Bendahara penerima mencatat dan merekapitulasi setiap penerimaan PKB sesuai dengan jumlah yang tertera pada SKPD pada buku kas pembantu dan mengisi Surat Tanda Setor (STS), bukti setoran, dan buku penyetoran bank.

7. Bendahara penerima menyampaikan laporan realisasi penerimaan harian dan laporan pertanggung jawaban secara fungsional pada bendahara penerima dan secara administratif pada kepala UPTD selaku pengguna anggaran paling lambat tanggal 5 (lima) bulan berikutnya dan menyampikan laporan pertanggungjawaban kepada Kepala Badan Pengelolaan Keuangan dan Barang Milik Daerah Provinsi Sulut selaku PPKD paling lambat tanggal 5 (lima) bulan berikutnya.

\subsection{Pembahasan}

Lingkungan pengendalian yang baik yaitu setiap prosedur harus memiliki SOP. Standar Operational Prosedur (SOP) yang ada pada pendaftaran ini saat diterimanya formulir 
oleh wajib pajak sudah sesuai dengan tugas yang staff masing-masing loket akan tetapi masih ada yang kurang dengan standar operational prosedur yang di mana tidak adanya bagian meja informasi untuk pelaksanaan petunjuk tahapan prosedur pendaftaran PKB. Mengidentifikasi risiko yang relevan terhadap pencapaian yaitu dengan penentuan "bagaimana risiko dinilai untuk kemudian dikelola" melalui rencana dan strategi serta kebijakan yang ditetapkan, salah satunya identifikasi risiko dalam prosedur pendaftaran membayar pajak kendaraan bermotor pihak Samsat telah menyediakan skema mekanisme dan syarat-syarat dokumen sehingga memudahkan wajib pajak mengerti dan memahami tata cara pendaftaran pembayaran PKB, namun belum tersedia bagian pelayanan informasi yang jelas dalam bentuk bagian meja informasi. Kebijakan dan prosedur yang dapat membantu mengarahkan manajemen hendaknya dilaksanakan. Aktivitas pengendalian kurangnya pemisahan tugas dan tanggung jawab antara petugas. Seperti yang sudah di ketahui tidak adanya bagian informasi atau front office hal ini membuat tugas dan tanggung jawab petugas menjadi tidak teridentifikasi dengan jelas. Tidak adanya posisi petugas yang memegang bagian pemeriksaan kelengkapan berkas membuat hal ini menjadi tanggung jawab petugas lain contohnya petugas pendaftaran atau staf lain. Petugas keamanan yang bertugas dan tanggung jawabnya sebagai keamanan pun menjadi tempat para wajib pajak mencari informasi atau melakukan bagian pemeriksaan seperti fotokopi KTP dan lampiran lainnya pada petugas keamanan yang ada.

Sistem informasi dan komunikasi yang merupakan kunci dari komponen pengendalian. Informasi dan komunikasi UPTD Samsat Manado antara wajib pajak dan staf belum optimal. Tidak adanya bagian informasi membuat wajib pajak sering melakukan kesalahan dalam pengisian formulir dan penyaluran dokumen di tiap bagian pelayanan yang ada. Persyaratan dokumen yang harus dipenuhi wajib pajak guna kelengkapan, misalnya fotokopi KTP, BPKB, STNK dan SKPD. Wajib pajak seringkali terkendala dengan ketiadaan informasi tentang persyaratan dokumen yang menjadi lampiran. Lingkungan pengendalian merupakan acuan dasar disiplin dan etika, dalam lingkungan pengendalian etika petugas sudah baik. Begitu pun dengan tugas dan tanggung jawab sudah sesuai, dalam hal prosedur dan tugas petugas penetapan, petugas korektor, dan bendahara penerima. Kemudahan bagi wajib pajak dalam melakukan penyetoran dan pembayaran pada UPTD Samsat Manado karena sudah adanya petunjuk yang sesuai pada tiap loket. Ketepatan waktu dan integritas para staf sudah baik begitu pula dengan manajemen dalam pembayaran PKB. Prosedur pembayaran PKB pengendalian internal sejauh ini sudah diterapkan dengan baik. Walaupun untuk sistem harus lebih dikembangkan lagi bagaimana pemecahan masalahnya karena sistem ini menggunakan jaringan yang bisa menghambat pembayaran jika terjadi gangguan pada jaringan. Penyetoran dan pembayaran PKB aktivitas pengendalian sudah baik, di mana setiap petugas menjalankan tugas dengan baik seperti memverifikasi slip dan juga petugas loket yang memberikan stempel bukti pelunasan. Informasi dan komunikasi antara petugaspetugas loket dan wajib pajak sudah baik, di mana hal ini terlihat dari tiap proses yang di lakukan wajib pajak dari pembayaran kemudian proses pemberian stempel bukti pelunasan.

Lingkungan pengendalian merupakan dasar dari komponen pengendalian yang lain, di mana dasar-dasar dalam semua proses seperti tanggung jawab dan manajemen di dalam menjalankan tugas. Proses penerimaan kas sudah terkendali dengan baik dalam hal proses penetapan sampai dengan proses pencatatan. Begitu pun dengan manajemen fungsi akuntansi tidak ada kekeliruan dalam pencatatan. Penilaian risiko dimana risiko-risiko yang ada akan identifikasi kemudian dinilai untuk dikelola, dalam hal ini akan ada risiko saat penerimaan kas di mana jika terjadinya gangguan pada sistem pembayaran langsung ke bank. Dapat mengganggunya proses penerimaan PKB. Tetapi di sisi lain fungsi akuntansi yang mencatat penerimaan kas sangat bermanfaat dalam proses penerimaan PKB yang di mana bisa di pantau penerimaan kas setiap bulannya melalui pencatatan yang ada pada Kantor Samsat. 
Proses penerimaan kas memiliki aktivitas pengendalian yang meliputi aktivitasaktivitas verifikasi dan inspeksi dan telah di jalankan dengan baik. Dimulai dari proses fungsi kas yang memeriksa hasil print out wajib pajak dengan menggunakan nomor urut, adanya bagian pencatatan yang digunakan untuk membuat laporan penerimaan kas bulanan, dimana bendahara penerima melakukan verifikasi dan kemudian menerbitkan STS yang sah yang di tunjukkan kepada bank dan wajib pajak. Wajib pajak dan petugas tiap loket sudah memiliki standar informasi dan komunikasi yang baik, dimana dalam penerimaan kas wajib pajak melalui prosedur verifikasi, pencatatan sampai dengan penerimaan bukti STS yang hanya dimiliki bank dan wajib pajak. Sistem informasi dan komunikasi yang ditetapkan oleh Dispenda untuk UPTD Samsat Manado telah terkomputerasi dan dijalankan secara online. Adanya pengelolaan keuangan berbasis teknologi menunjukkan bahwa sistem ini menunjang Samsat untuk melakukan pengecekan PKB, rangkaian penerimaan atau pemungutan pajak bisa di lihat melalui sistem ini.

Integritas tiap pegawai dalam menjalankan tugas sesuai dengan standar pengendalian yang ada. Tiap proses prosedur di jalankan sesuai tugas masing-masing tanpa melibatkan staf yang tidak memiliki tanggung jawab yang sama. Petugas dengan mudah menerima hasil penetapan pajak karena adanya pengawasan yang baik dari prosedur pendaftaran dan pembayaran PKB. Mengidentifikasi risiko yaitu melalui rencana dan strategi serta kebijakan yang ditetapkan, dalam pelaporan Pajak Kendaraan Bermotor (PKB) risiko yang ada bisa ditemui saat pencetakan SPKD, jumlah petugas pencetak SKPD perlu di tambah agar wajib pajak tidak perlu menunggu terlalu lama saat akan mencetak SKPD. Selebihnya pelaporan PKB semua sudah sesuai dengan standar yang ada dari penerimaan, pencatatan, verifikasi, sampai dengan rekapitulasi.

Kebijakan dan prosedur yang dapat membantu mengarahkan manajemen hendaknya dilaksanakan. Pendokumentasian dan pencatatan yang memadai telah dijalankan sesuai dengan prosedur begitu pun dengan struktur manajemen yang ada seperti pelaporan dokumen SKPD atau pemberitahuan pajak. Setiap petugas menjalankan tugas sesuai dengan tanggung jawab mereka. Aktivitas pengendalian yang telah diterapkan sudah cukup efektif dan memadai. Informasi dan komunikasi menampung kebutuhan perusahaan di dalam mengidentifikasi, mengambil, dan mengomunikasikan informasi-informasi kepada pihak yang tepat agar mereka mampu melaksanakan tanggung jawab mereka. Proses pelaporan PKB memiliki komunikasi dan informasi antara petugas tiap loket yang sangat baik, yaitu petugas pencetakan, bendahara penerima, hingga petugas penyerahan, Informasi dan komunikasi sudah berjalan baik dalam prosedur pelaporan, seluruh dokumen disimpan dengan baik dan terorganisir dalam hal ini bendahara penerimaan memiliki tanggung jawab informasi secara administratif pada kepala UPTD selaku pengguna anggaran.

\section{KESIMPULAN DAN SARAN}

\subsection{Kesimpulan}

Kesimpulan atas penelitian adalah:

1. Sistem dan prosedur pemungutan PKB pada UPTD Samsat Manado tahap pendaftaran telah berjalan dengan cukup baik sesuai dengan pemisahan fungsi dan tugas yang telah ditetapkan untuk masing-masing petugas.

2. Sistem dan prosedur pemungutan PKB pada UPTD Samsat Manado dalam tahap penetapan dan penyetoran sudah berjalan dengan baik namun belum bisa dikatakan efektif karena hanya memakai satu sistem pembayaran secara online sehingga masih ada hal yang menghambat wajib pajak dalam pembayaran pajak dikarenakan terjadi gangguan jaringan. 
3. Sistem dan prosedur pemungutan PKB pada UPT Samsat saat tahap pelaporan telah dijalankan dengan baik namun pelayanan pencetakan SKPD perlu di perbaiki untuk meminimalisir antrian wajib pajak.

4. UPTD Samsat Manado sudah menerapkan prinsip-prinsip pengendalian internal cukup baik.

\subsection{Saran}

Saran atas penelitian ini adalah:

1. Unit Pelaksanaan Teknis Dinas Samsat Manado sebaiknya menerapkan alternatif yang lain misalnya pembayaran melalui sistem online.

2. Penilaian risiko pada Unit Pelaksanaan Teknis Dinas Samsat Manado perlu di perhatikan, khususnya dalam hal kedisiplinan pegawai.

\section{DAFTAR PUSTAKA}

Agustin, N. S., \& Putra, R. E. (2019). Pengaruh kesadaran masyarakat, sanksi perpajakan dan kualitas pelayanan terhadap kepatuhan wajib pajak dalam membayar pajak kendaraan bermotor pada Samsat Kota Batam. Measurement: Jurnal Akuntansi, 13(1), 57-64. https://www.journal.unrika.ac.id/index.php/measurement/article/view/1833

Anggoro, D. D. (2017). Pajak daerah dan retribusi daerah, Edisi 1. Malang: Universitas Brawijaya Press.

George, S. C. S., Pangemanan, S. S., \& Wokas, H. (2017). Implementasi pengelolaan kebijakan pengalokasian dana pajak dari bagi hasil atas pajak kendaraan bermotor terkait peruntukannya di provinsi Sulawesi Utara. Going Concern: Jurnal Riset Akuntansi, 12(1), 54-62. https://doi.org/10.32400/gc.12.01.17137.2017

Kansil, T. A. M., Kalangi, L., \& Budiarso, N, S. (2018). Analisis efektivitas, kontribusi dan potensi pajak kendaraan bermotor sebagai sumber pendapatan asli daerah di provinsi Sulawesi Utara. Going Concern: Jurnal Riset Akuntansi, 12(4), 441-450. https://doi.org/10.32400/gc.13.04.21194.2018

Madundang, C. K., \& Ilat, V. (2014). Analisis perhitungan pajak kendaraan bermotor dan bea balik nama di Kantor Bersama Samsat Bitung. Jurnal EMBA: Jurnal Riset Ekonomi, Manajemen, Bisnis dan Akuntansi, 2(4), 90-99. https://ejournal.unsrat.ac.id/index.php/emba/article/view/6221

Panjaitan, N. J., \& Simarmata, H. M. P. (2018). Pengaruh pajak kendaraan bermotor terhadap pendapatan pajak daerah. Jurnal Ekonomi dan Bisnis, 1(1), 1-11. http://jurnal.murnisadar.ac.id/index.php/EKBI/article/view/39

Peraturan Daerah Provinsi Sulawesi Utara Nomor 7 Tahun 2011 Tentang Pajak Daerah.

Undang-Undang Republik Indonesia Nomor 28 Tahun 2009 Pajak Daerah dan Retribusi Daerah.

Undang-Undang Republik Indonesia Nomor 17 tahun 2003 Tentang Keuangan Negara.

Undang-Undang Republik Indonesia Nomor 34 Tahun 2000 Tentang perubahan atas UndangUndang Republik Indonesia Nomor 18 Tahun 1997.

Peraturan Pemerintah Provinsi Sulawesi Utara Nomor 65 Tahun 2001 Tentang Pajak Daerah.

Sari, D. (2013). Konsep dasar perpajakan, Edisi 1. Bandung: PT Refika Aditama.

Sayuti, N., \& Faisal, A. M. (2014). Kualitas pelayanan pajak kendaraan bermotor dan bea balik nama kendaraan bermotor di provinsi Sulawesi Selatan. Jurnal Administrasi Negara, 20(3), 133-143. https://www.e-jurnal.com/2016/05/kualitas-pelayanan-pajakkendaraan.html

Wardani, D. K., \& Juliansya, F. (2018). Pengaruh program e-Samsat terhadap kepatuhan wajib pajak kendaraan bermotor dengan kepuasan kualitas pelayanan sebagai variabel intervening (Studi kasus Samsat Daerah Istimewa Yogyakarta). Jurnal Akuntansi \& 
Manajemen Akmenika, 15(2), 79-92. http://manajemen.upy.ac.id/manajemen/wpcontent/uploads/2016/12/1.-Dewi-Kusuma-Wardani.pdf

Wibowo, \& Arif, A. (2008). Akuntansi keuangan dasar 1: Ikhtisar teori, soal-soal, dan materi praktis, Edisi 3. Jakarta: Grasindo. 